\title{
Cadmium-induced ammonium ion accumulation of rice seedlings at high temperature is mediated through abscisic acid
}

\author{
Yi Ting Hsu $\cdot$ Mei Chun Kuo $\cdot$ Ching Huei Kao
}

Received: 21 February 2006/ Accepted: 28 June 2006/Published online: 24 August 2006

(C) Springer Science+Business Media B.V. 2006

\begin{abstract}
In this study, we examined interaction between cadmium $(\mathrm{Cd})$ and temperature in rice seedlings. Effects of $\mathrm{CdCl}_{2}(0.5 \mathrm{mM})$ simultaneously applied at high $\left(35 / 30^{\circ} \mathrm{C}\right.$ day/night $)$, medium $\left(25 / 20^{\circ} \mathrm{C}\right)$ and low $\left(15 / 13^{\circ} \mathrm{C}\right)$ temperatures to rice seedlings were detected by measuring changes in biomass production and $\mathrm{NH}_{4}^{+}$ content. Results indicated that Cd-induced biomass reduction and $\mathrm{NH}_{4}^{+}$accumulation increased in parallel with temperature increases. On treatment with $\mathrm{CdCl}_{2}$, the abscisic acid (ABA) content markedly increased in the leaves of seedlings grown at high temperature but not at medium and low temperatures. Exogenous application of ABA at medium temperature increased ABA and $\mathrm{NH}_{4}^{+}$contents in the leaves of rice seedlings. Fluridone (Flu) treatment, an inhibitor of carotenoid biosynthesis, reduced ABA content, as well as $\mathrm{Cd}$-induced $\mathrm{NH}_{4}^{+}$accumulation in the leaves of rice seedlings grown at high temperature. These Flu effects can be reversed by application of ABA. Furthermore, Flu treatment did not reduce $\mathrm{Cd}$ content in leaves of seedlings grown at high temperature. All these results suggest that $\mathrm{Cd}$ induced $\mathrm{NH}_{4}^{+}$accumulation at high temperature is mediated through ABA.
\end{abstract}

Y. T. Hsu · M. C. Kuo · C. H. Kao ( $ه)$ Department of Agronomy, National Taiwan University, Taipei, Taiwan, Republic of China e-mail: kaoch@ntu.edu.tw
Keywords Abscisic acid · Ammonium ion · Cadmium $\cdot$ Oryza sativa $\cdot$ Temperature

$\begin{array}{ll}\text { Abbreviations } \\ \text { ABA } & \text { Abscisic acid } \\ \text { DW } & \text { Dry weight } \\ \text { ELISA } & \text { Enzyme-linked immunosorbent assay } \\ \text { Flu } & \text { Fluridone } \\ \text { GS } & \text { Glutamine synthetase } \\ \text { NCED } & \text { 9-cis-epoxycarotenoid dioxygenase } \\ \text { PAL } & \text { Phenylalanine ammonia-lyase }\end{array}$

\section{Introduction}

Cadmium (Cd) is a divalent heavy metal cation and is one of the most toxic heavy metals. It is supplied to soil, air, and water mainly by effluents from industries, mining, burning, and leakage waste, and by application of phosphate and sewage sludge. $\mathrm{Cd}$ is readily taken up by plants, leading to inhibition of physiological processes such as respiration, photosynthesis, cell elongation, plant-water relationships, nitrogen metabolism, and mineral nutrition (Sanitá di Toppi and Gabbrielli 1999).

Global warming, accompanied by an increased frequency of periods with exceptionally high 
temperatures, is one of the most important characteristics of the accelerated climatic changes. Climatic models predict that global temperature will continue to increase in the future. Peng et al. (2004) analyzed weather data at the International Rice Research Institute Farm from 1979 to 2003 to examine temperature trends and reported that annual mean maximum and minimum temperatures have increased by $0.35^{\circ} \mathrm{C}$ and $1.13^{\circ} \mathrm{C}$, respectively. Hence, plants will be more often exposed to high temperature conditions. It has been shown that $\mathrm{Cd}$ toxicity (the reduction of plant height, the decrease in chlorophyll content, and the accumulation of phenolic compounds and proline) of wheat seedlings increases in parallel to temperature increases (Öncel et al. 2000). Temperature is a key factor in altering ion accumulation (Chawla et al. 1991; Hooda and Alloway 1993; Macek et al. 1994; Mautsoe and Beckett 1996). The high toxicity of Cd induced by high temperature may be the results of much more $\mathrm{Cd}$ uptake from the medium.

$\mathrm{NH}_{4}^{+}$is a central intermediate of nitrogen metabolism (Miflin and Lea 1976). It has been shown that on treatment with $\mathrm{CdCl}_{2}, \mathrm{NH}_{4}^{+}$content increased in rice leaves (Hsu and Kao 2003). Glutamine synthetase (GS) is the key enzyme in $\mathrm{NH}_{4}^{+}$assimilation and catalyzes the ATP-dependent condensation of $\mathrm{NH}_{4}^{+}$with glutamate to produce glutamine (Miflin and Lea 1976). Phenylalanine ammonia-lyase (PAL) catalyzes the elimination of $\mathrm{NH}_{4}^{+}$from phenylalanine and produces trans-cinnamate (Hahlbrock and Grisebach 1979). $\mathrm{NH}_{4}^{+}$, released from PAL reaction, is known to be trapped in the glutamine molecule by the action of GS (Razel et al. 1996; van Heerden et al. 1996). Sakurai et al. (2001) provided evidence to show that GS is partly coupled to the reaction of PAL in developing rice leaves. Cd-induced $\mathrm{NH}_{4}^{+}$accumulation in rice leaves has been proved to be associated with the decrease in GS activity and the increase in PAL specific activity (Hsu and Kao 2004).

The plant hormone ABA is a sesquiterpenoid derived from xanthophyll (Nambara and MarionPoll 2005) and appears to influence several physiological and developmental events (Seo and Koshiba 2002; Zeevaart and Creelman 1988). The level of ABA in plant tissues is known to increase in reponse to exposure to heavy metals such as Cd, Ni, Zn, and Al (Fediuc et al. 2005; Foy 1998; Hollenbach et al. 1997; Hsu and Kao 2003; Poschenrieder et al. 1989; Rauser and Dumbroff 1981). Fediuc et al. (2005) demonstrated that Cdinduced ABA accumulation was observed in roots, but not shoots, of Typha and Phragmites plants. Hsu and Kao (2003) found that, on treatment with $\mathrm{CdCl}_{2}$, the ABA content rapidly increased in the leaves and roots in Cd-tolerant rice cultivar (cv. Tainung 67) grown at normal growing temperature $\left(30 / 25^{\circ} \mathrm{C}\right.$, day/night) but not in Cd-sensitive cultivar (cv. Taichung Native 1).

In this study, effects of Cd applied at low (15/ $13^{\circ} \mathrm{C}$ day/night $)$, medium $\left(25 / 20^{\circ} \mathrm{C}\right.$ day/night $)$, and high $\left(35 / 30^{\circ} \mathrm{C}\right.$ day/night $)$ temperatures on the content of $\mathrm{NH}_{4}^{+}$in leaves of rice seedlings were compared. Recently, we showed that ABA treatment resulted in an accumulation in $\mathrm{NH}_{4}^{+}$in detached rice leaves (Hung and Kao 2005). We thus examined the possibility that ABA plays a role in mediating the $\mathrm{Cd}$-induced $\mathrm{NH}_{4}^{+}$accumulation in leaves of rice seedlings grown at high temperature.

\section{Materials and methods}

Plant material and treatments

Rice (Oryza sativa L., cv. Taichung Native 1) seeds were sterilized with $2.5 \%$ sodium hypochlorite for $15 \mathrm{~min}$ and washed extensively with distilled water. These seeds were then germinated in Petri-dishes with wetted filter papers at $37^{\circ} \mathrm{C}$ in the dark. After $48 \mathrm{~h}$ incubation, uniformly germinated seeds were selected and cultivated in a $250 \mathrm{ml}$ beaker containing half-strength Kimura B solution containing the following macro- and micro-elements: $182.3 \mu \mathrm{M}\left(\mathrm{NH}_{4}\right)_{2} \mathrm{SO}_{4}, 91.6 \mu \mathrm{M}$ $\mathrm{KNO}_{3}, 273.9 \mu \mathrm{M} \mathrm{MgSO}_{4} \cdot 7 \mathrm{H}_{2} \mathrm{O}, 91.1 \mu \mathrm{M} \mathrm{KH}_{2} \mathrm{PO}_{4}$, $182.5 \mu \mathrm{M} \mathrm{Ca}\left(\mathrm{NO}_{3}\right)_{2}, 30.6 \mu \mathrm{M}$ Fe-citrate, $0.25 \mu \mathrm{M}$ $\mathrm{H}_{3} \mathrm{BO}_{3}, 0.2 \mu \mathrm{M} \quad \mathrm{MnSO}_{4} \cdot \mathrm{H}_{2} \mathrm{O}, 0.2 \mu \mathrm{M} \quad \mathrm{ZnSO}_{4} \cdot 7-$ $\mathrm{H}_{2} \mathrm{O}, \quad 0.05 \mu \mathrm{M} \quad \mathrm{CuSO}_{4} \cdot 5 \mathrm{H}_{2} \mathrm{O}$, and $0.07 \mu \mathrm{M}$ $\mathrm{H}_{2} \mathrm{MoO}_{4}$. The nutrient solutions ( $\mathrm{pH}$ 4.7) were replaced every 3 days. The hydroponically cultivated seedlings were grown in a Phytotron (Agricultural Experimental Station, National Taiwan University, Taipei, Taiwan) with natural sunlight at $30 / 25^{\circ} \mathrm{C}$ day/night and $90 \%$ relative humidity. 
Twelve-day-old seedlings with three leaves were grown in basic nutrient solution with or without $\mathrm{CdCl}_{2}$ at high $\left(35 / 30^{\circ} \mathrm{C}\right.$ day/night), medium (25/ $20^{\circ} \mathrm{C}$ day/night $)$, or low temperature $\left(15 / 13^{\circ} \mathrm{C}\right.$ day/ night). Based on our experience from the experiments of $\mathrm{Cd}$ effect on rice seedlings, consistent $\mathrm{Cd}$ toxicity was observed in 2 days when $0.5 \mathrm{mM} \mathrm{CdCl}_{2}$ was used for experiments. However, no consistent $\mathrm{Cd}$ toxicity was observed when lower $\mathrm{CdCl}_{2}$ concentrations, in the range 5-50 mM, were applied over a longer period ( 6 days). For this reason in this study, $0.5 \mathrm{mM} \mathrm{CdCl}_{2}$ was used and added directly to nutrient solution. For the experiments in which the effect of exogenous ABA was examined, various concentrations of ABA (5-40 mM, mixed isomers) were added directly to the culture solution for 2 days at medium temperature. In experiments to understand the role of endogenous ABA, $0.2 \mathrm{mM}$ fluridone (Flu), which is known to block the conversion of phytoene to phytofluene in carotenoid biosynthesis pathway (Kowalczyk-Schröder and Sandmann 1992), was added directly to the nutrient solution for 2 days.

Growth analysis

At the end of treatment, the seedlings were divided into separate parts (shoot, and roots). The dry weight (DW) of the shoot and roots (adventitious roots plus primary roots) were then measured. For DW estimation, the shoot and roots were dried at $65^{\circ} \mathrm{C}$ for $48 \mathrm{~h}$.

\section{Cd determination}

For determination of $\mathrm{Cd}$, leaves were dried at $65^{\circ} \mathrm{C}$ for $48 \mathrm{~h}$. Dried material was ashed at $550^{\circ} \mathrm{C}$ for $20 \mathrm{~h}$. The ash residue was incubated with $31 \%$ $\mathrm{HNO}_{3}$ and $17.5 \% \mathrm{H}_{2} \mathrm{O}_{2}$ at $72^{\circ} \mathrm{C}$ for $2 \mathrm{~h}$, and dissolved in distilled water. $\mathrm{Cd}$ was then quantified using an atomic absorption spectrophotomer (Model AA-6800, Shimadzu, Kyoto, Japan). Amount of $\mathrm{Cd}$ is expressed on the basis of DW.

Determinations of protein, $\mathrm{NH}_{4}^{+}$, and abscisic acid

For protein determination, leaves were homogenized in a $50 \mathrm{mM}$ sodium phosphate buffer $(\mathrm{pH}$
6.8). The extracts were centrifuged at $17,600 \mathrm{~g}$ for $20 \mathrm{~min}$, and the supernatants were used for determination by the method of Bradford (1976). $\mathrm{NH}_{4}^{+}$was measured in the crude extract by the Berthelot reaction, modified according to Weatherburn (1967). The detailed procedure was described previously (Lin and Kao 1996). $\mathrm{NH}_{4}^{+}$ contents are expressed on the basis of DW.

For extraction of ABA, leaves were homogenized with a pestle and mortar in extraction solution (80\% methanol containing $2 \%$ glacial acetic acid). To remove plant pigments and other non-polar compounds which could interfere in the immunoassay, extracts were first passed through polyvinylpyrrolidone column and C18 (Sep-Pak Vac) cartridges (Waters, Milford, MA). The eluates were concentrated to dryness by vacuum-evaporation and resuspended in Trisbuffered saline before enzyme-linked immunosorbent assay (ELISA). ABA was quantified by ELISA (Walker-Simmons, 1987). ABA immunoassay detection kit (PGR-1) was purchased from Sigma Chemical Co. (St. Louis, MO) is specific for (+)-ABA. By evaluating ${ }^{3} \mathrm{H}-\mathrm{ABA}$ recovery, ${ }^{3} \mathrm{H}$-ABA loss was $(3 \%$ by the method described here. ABA content is expressed on the basis of DW.

\section{Enzyme assays}

For extraction of GS, leaf samples were homogenized with $10 \mathrm{mM}$ Tris-HCl buffer $(\mathrm{pH}$ 7.6, containing $1 \mathrm{mM} \mathrm{MgCl}, 1 \mathrm{mM}$ EDTA, and $1 \mathrm{mM}$ 2-mercaptoethanol) using a chilled pestle and mortar. The homogenate was centrifuged at $15,000 \mathrm{~g}$ for $30 \mathrm{~min}$ and the resulting supernatant was used for determination of GS activity. The whole extraction procedure was carried out at $4^{\circ} \mathrm{C}$. GS was assayed by the method of Oaks et al. (1980). The reaction mixture contained in a final volume of $1 \mathrm{ml}$ was $80 \mu \mathrm{mol}$ Tris- $\mathrm{HCl}$ buffer, $40 \mu \mathrm{mol}$ L-glutamic acid, $8 \mu \mathrm{mol}$ ATP, $24 \mu \mathrm{mol}$ $\mathrm{MgSO}_{4}$, and $16 \mu \mathrm{mol} \mathrm{NH} \mathrm{NH}_{2} \mathrm{OH}$; the final $\mathrm{pH}$ was 8.0. The reaction was started by addition of the enzyme extract and, after incubation for $30 \mathrm{~min}$ at $30^{\circ} \mathrm{C}$, was stopped by adding $2 \mathrm{ml} 2.5 \%$ (w/v) $\mathrm{FeCl}_{3}$ and $5 \%(\mathrm{w} / \mathrm{v})$ trichloroacetic acid in $1.5 \mathrm{M}$ $\mathrm{HCl}$. After centrifugation the absorbance of the supernatant was read at $540 \mathrm{~nm}$. One unit of 
GS activity is defined as $1 \mu \mathrm{mol}$ L-glutamate $\gamma$-monohydroxamate formed per min.

Phenylalanine ammonia-lyase (PAL) was extracted and determined according to Hyodo and Fujinami (1989). The calculation was based on the extinction coefficient $\left(9500 \mathrm{M}^{-1} \mathrm{~cm}^{-1}\right)$ for transcinnamic acid. One unit of activity for PAL was defined as the amounts of enzyme which caused the formation of $1 \mu \mathrm{mol}$ trans-cinnamic acid per hour.

\section{Transpiration rate}

The transpiration rate was measured according to Greger and Johansson (1992). The weight of rice seedlings grown in hydroponic solution was determined at the beginning and the end of interval, respectively. The transpiration rate was calculated for the water loss during each interval and converted to a per day per seedling basis.

Statistical analysis

Statistical differences between measurements $(n=4)$ on different treatments or on different times were analyzed following LSD test.

\section{Results}

\section{Biomass production}

In the absence of $\mathrm{CdCl}_{2}$, no significant difference in shoot DW of rice seedlings treated with different temperatures was observed (Fig. 1A). $\mathrm{CdCl}_{2}$ treatment resulted in a $15 \%$ reduction of shoot DW at high temperature but not at low and medium temperatures (Fig. 1A). Low temperature treatment had lower root DW of rice seedlings in the absence of $\mathrm{CdCl}_{2}$ than medium and high temperatures (Fig. $1 \mathrm{~B}$ ). $\mathrm{CdCl}_{2}$ treatment reduced root DW to the level of $70 \%$ of the untreated seedlings at high and medium temperatures (Fig. 1B). However, Cd had no effect on root DW at low temperature (Fig. 1B).

\section{Effect of temperatures on $\mathrm{NH}_{4}^{+}$content}

$\mathrm{NH}_{4}^{+}$is a central intermediate of nitrogen metabolism in plants (Miflin and Lea 1976). Here,
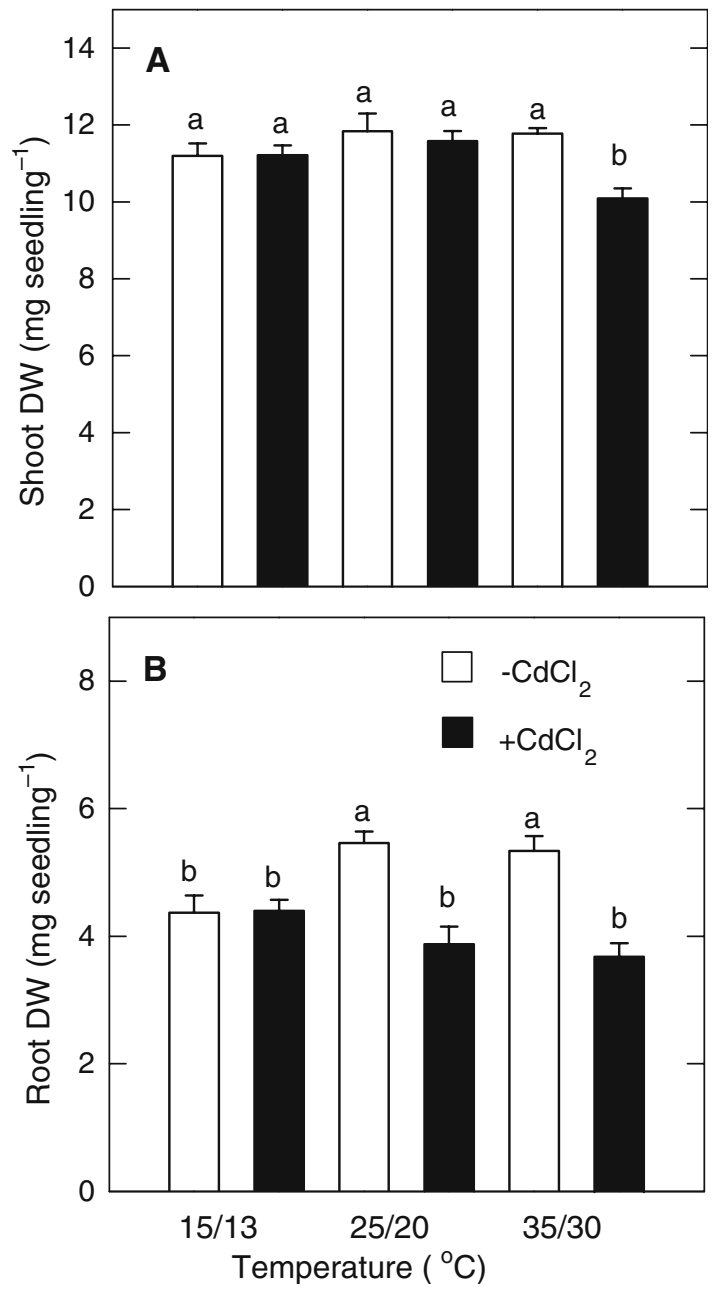

Fig. 1 Effect of temperatures on the dry weight of shoot (A) and roots (B) of rice seedlings treated with or without $\mathrm{CdCl}_{2}(0.5 \mathrm{mM})$. All measurements were made two days after treatment. Bars indicate standard error $(n=4)$. Values with the same letter are not significantly different at $P<0.05$

we show that on treatment with $\mathrm{CdCl}_{2}, \mathrm{NH}_{4}^{+}$ content increases about 3 -fold in the second leaves of rice seedlings grown at high temperature, but $80 \%$ at medium and low temperatures (Fig. 2A). At high temperature, $\mathrm{CdCl}_{2}$ treatment resulted in a $50 \%$ decrease in GS activity in the second leaves (Fig. 2B). However, there was no decrease in GS activity in the second leaves of rice seedlings treated with $\mathrm{CdCl}_{2}$ at medium and low temperatures (Fig. $2 \mathrm{~B}$ ). $\mathrm{CdCl}_{2}$ treatment resulted in about 3-fold increase in PAL specific activity in leaves of rice seedlings grown at high 

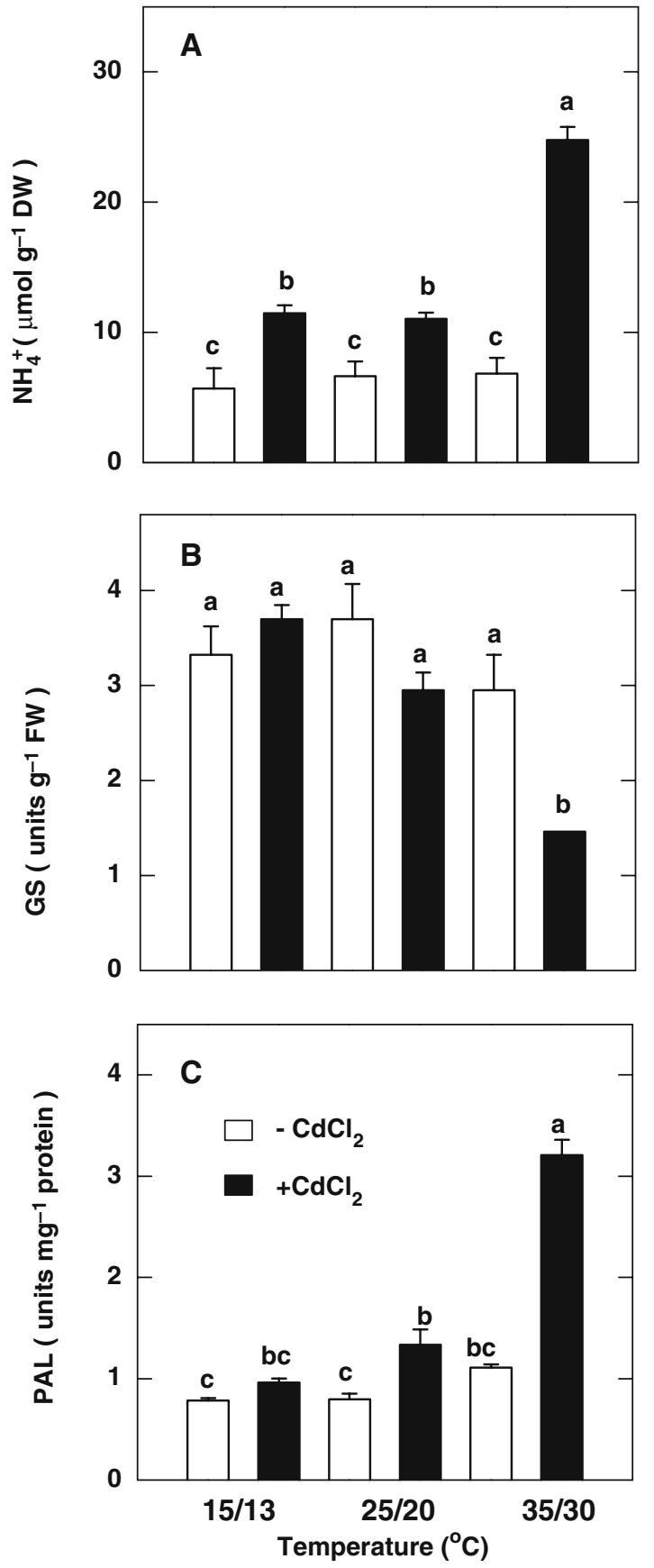

Fig. 2 Effect of temperatures on the contents of $\mathrm{NH}_{4}^{+}(\mathbf{A})$, and the activities of GS (B), and the specific activities of PAL $(\mathbf{C})$ in the second leaves of rice seedlings treated with or without $\mathrm{CdCl}_{2}(0.5 \mathrm{mM})$. All measurements were made two days after treatment. Bars indicate standard error $(n=4)$. Values with the same letter are not significantly different at $P<0.05$

temperature (Fig. 2C). However, slight (30\%) and no increase in PAL specific activity in the second leaves of rice seedlings treated with $\mathrm{CdCl}_{2}$ at medium and low temperatures, respectively (Fig. 2C).

\section{Effect of temperatures on Cd content}

$\mathrm{CdCl}_{2}$ treatment resulted in 30-, 11-, and 13-fold increase in $\mathrm{Cd}$ content in the third leaves (Fig. 3A), 32-, 3-, and 2.4-fold increase in the second leaves (Fig. 3B), and 69-, 48-, and 19-fold increase in roots (Fig. 3C) at high, medium, and low temperatures, respectively. The results in Figs. 3A-C are consistent with the idea that the amount of $\mathrm{Cd}$ reaching the shoot is usually lower than the amount in the roots (Javis et al. 1976). Figure 4 demonstrated that the increase in $\mathrm{Cd}$ content in the second leaves was evident 8,24 , and $36 \mathrm{~h}$ after $\mathrm{CdCl}_{2}$ treatment at high, medium, and low temperatures, respectively.

Effect of temperatures on transpiration rate and ABA content

Cd has been shown to decrease transpiration rate in several plants (Hagemeyer et al. 1986; Kirkham 1978; Lamoreaux and Chaney 1978; Schlegel et al. 1987). We also observed that Cd decreased transpiration rate in rice seedlings (Fig. 5A). $\mathrm{CdCl}_{2}$ treatment reduced transpiration rate of rice seedlings grown at low, medium, and high temperatures, respectively, to $53 \%, 29 \%$, and $13 \%$ of the control values (Fig. 5A). At high temperature, $\mathrm{CdCl}_{2}$ treatment resulted in about 3 -fold increase in endogenous ABA in the second leaves (Fig. 5B). However, 25\% and no increase in ABA content in the second leaves of rice seedlings treated with $\mathrm{CdCl}_{2}$ at medium and low temperatures, respectively (Fig. 5B).

\section{Exogenous application of ABA}

To study the effect of exogenous ABA, various concentrations of ABA $(5-40 \mu \mathrm{M})$ were added directly to the culture solution at medium temperature. The results indicated that exogenous ABA treatment increased endogenous ABA and $\mathrm{NH}_{4}^{+}$contents in the second leaves of rice seedlings grown at medium temperature (Figs. 6A, B). 

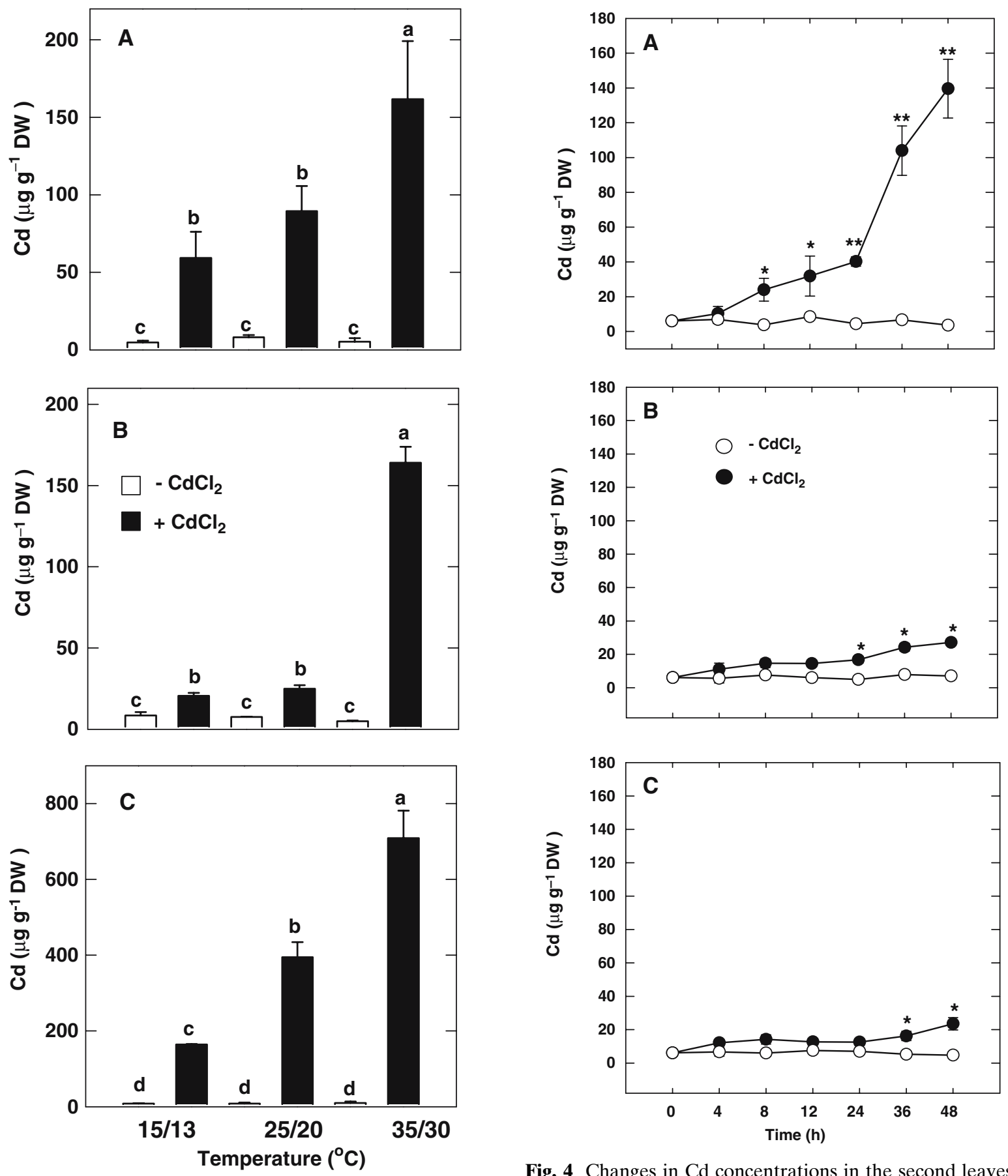

Fig. 3 Effect of temperatures on $\mathrm{Cd}$ concentrations in the third leaves $(\mathbf{A})$, the second leaves $(\mathbf{B})$, and roots $(\mathbf{C})$ of rice seedlings treated with or without $\mathrm{CdCl}_{2}(0.5 \mathrm{mM}) . \mathrm{Cd}$ concentrations were determined 2 days after treatment. Bars indicate standard error $(n=4)$. Values with the same letter are not significantly different at $P<0.05$

Fig. 4 Changes in Cd concentrations in the second leaves of rice seedlings treated with or without $\mathrm{CdCl}_{2}(0.5 \mathrm{mM})$ at $35 / 30^{\circ} \mathrm{C}(\mathbf{A}), 25 / 20^{\circ} \mathrm{C}(\mathbf{B})$, and $15 / 13^{\circ} \mathrm{C}(\mathbf{C})$. Bars indicate standard error $(n=4)$. Asterisks represent values that are significant between $-\mathrm{CdCl}_{2}$ and $+\mathrm{CdCl}_{2}$ treatments at $P<0.05$ 

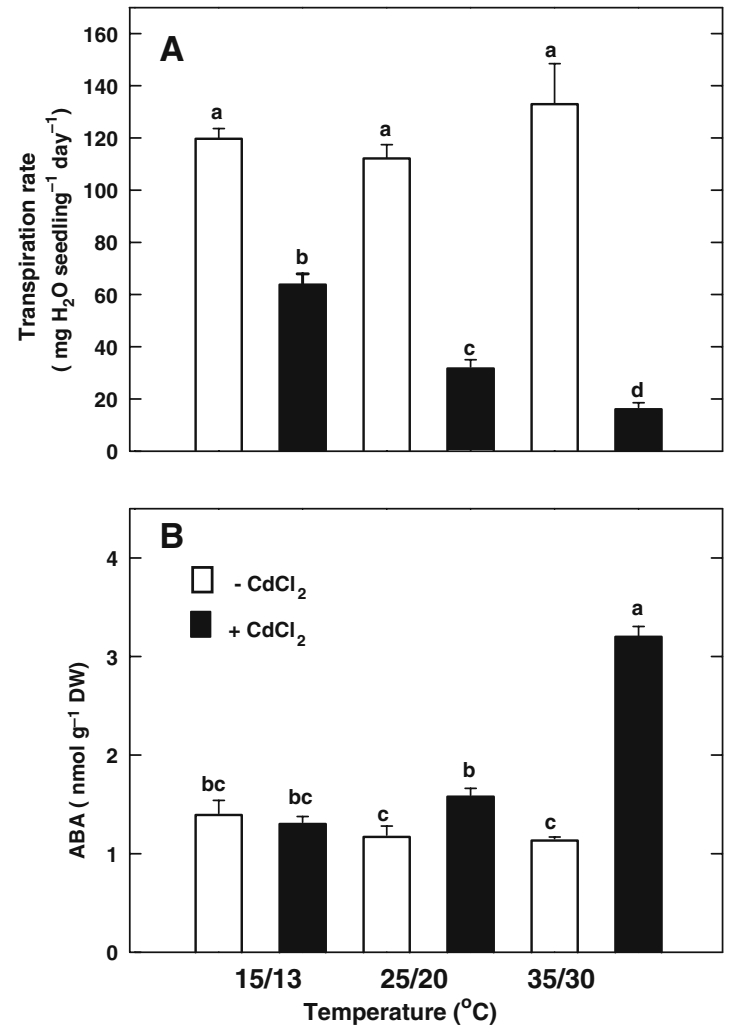

Fig. 5 Effect of temperatures on transpiration rates (A) and (B) ABA contents in the second leaves of rice seedlings treated with or without $\mathrm{CdCl}_{2}(0.5 \mathrm{mM})$. ABA contents were determined 2 days after treatment. Bars indicate standard error $(n=4)$. Values with the same letter are not significantly different at $P<0.05$

Fluridone treatment

The role of ABA in Cd-induced increase in $\mathrm{NH}_{4}^{+}$ content at high temperature was tested further by using Flu, which blocks the conversion of phytoene to phytofluene in cartenoid biosynthesis pathway (Kowalczyk-Schröder and Sandmann 1992). Flu treatment was observed to inhibit the increase in $\mathrm{ABA}$ content caused by $\mathrm{CdCl}_{2}$ (Fig. 7A) and reduce Cd-induced accumulation of $\mathrm{NH}_{4}^{+}$(Fig. 8A), decrease in GS activity (Fig. 8B), and increase in PAL specific activity (Fig. 8C) in the second leaves of rice seedlings grown at high temperature. The effects of Flu on reducing Cdinduced increase in $\mathrm{NH}_{4}^{+}$content and PAL specific activity, and the decrease in GS activity can be reversed by the application of ABA (Figs. 8A-C). ABA alone was also found to be able to increase $\mathrm{NH}_{4}^{+}$content and PAL specific activity and to decrease GS activity in the second leaves of rice seedlings grown at high temperature when compared with untreated control (Figs. $8 \mathrm{~A}-\mathrm{C}$ ). Figs. 7B, C also show that $\mathrm{Cd}$ content in the second leaves and transpiration rate of rice seedlings treated with Flu plus $\mathrm{CdCl}_{2}$ at high temperature are similar to those with $\mathrm{CdCl}_{2}$ alone.

\section{Discussion}

The interactive effects of temperature and heavy metal stress $(\mathrm{Cd}$ and $\mathrm{Pb})$ on the growth and some biochemical compounds have been studied in wheat seedlings (Öncel et al. 2000). In general, Cd toxicity (reduction of plant height, decrease in chlorophyll content, and accumulation of phenolic compounds) of wheat seedlings increases in parallel to temperature increases (Öncel et al. 2000). In rice seedlings, Cd-induced biomass reduction and $\mathrm{NH}_{4}^{+}$accumulation are also in parallel to temperature increases (Figs. 1A, B and 2A). The high biomass reduction and $\mathrm{NH}_{4}^{+}$accumulation caused by $\mathrm{CdCl}_{2}$ at high temperature seem to be a result of more and rapid Cd uptake from the medium (Figs. 3A-C and 4A-C). It has been shown that enhanced temperature increased the uptake of $\mathrm{Cd}$ in Solanum nigrum (Macek et al. 1994), Lemna minor (Chawla et al. 1991), Lolium perenne (Hooda and Alloway 1993), and mosses (Mautsoe and Beckett 1996). The massive difference (7-fold) in Cd uptake in the leaves of rice seedlings grown at high and medium temperatures suggests that the uptake of $\mathrm{Cd}$ in rice seedlings is also temperature-dependent. In the present study, rice seedlings were exposed to different air temperatures. In our system, high air temperature treatment resulted in high root temperature in about $1 \mathrm{~h}$ after treatment (unpublished data). A great body of evidence has demonstrated that $\mathrm{Cd}$ is taken by the roots via essential metal transporters (Cohen et al. 1998; Korshunova et al. 1999; Lasat et al. 2000; Pence et al. 2000; Salt et al. 1995). It is not known whether high root temperature increases the activities of metal transporters or Cd uptake in rice roots in the presence of $\mathrm{Cd}$. Further research in this direction is likely to be highly rewarding. 

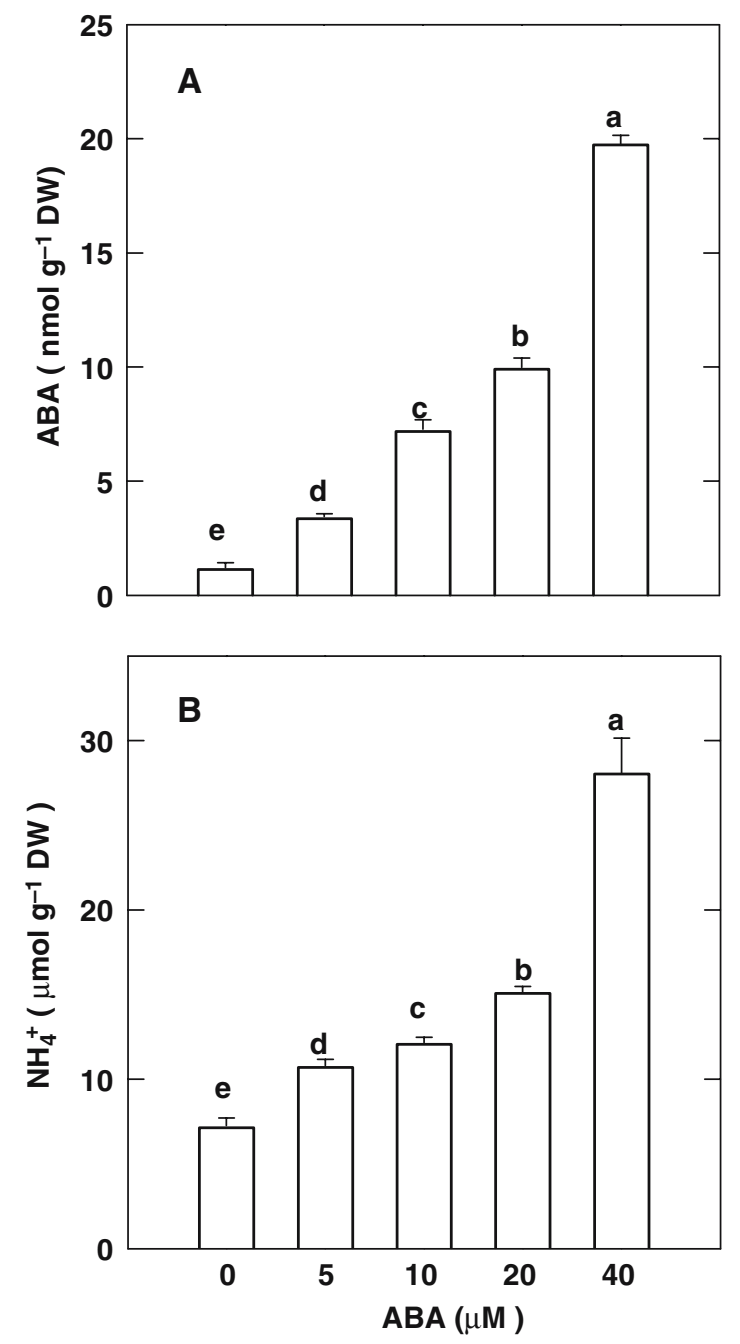

Fig. 6 Effect of ABA concentration on the content of ABA (A) and $\mathrm{NH}_{4}^{+}$(B) in the second leaves of rice seedlings grown at medium temperature. All measurements were made two days after treatment. Bars indicate standard error $(n=4)$. Values with the same letter are not significantly different at $P<0.05$

It has been shown that the decrease in GS activity and the increase on PAL activity are responsible for $\mathrm{NH}_{4}^{+}$accumulation in Cd-treated rice leaves (Hsu and Kao 2004). Here, we also show that on treatment with $\mathrm{CdCl}_{2}$, the decrease in GS activity and the increase in PAL specific activity and $\mathrm{NH}_{4}^{+}$content are more pronounced in the leaves of rice seedlings grown at high temperature than those at medium and low temperatures (Figs. 2B, C).
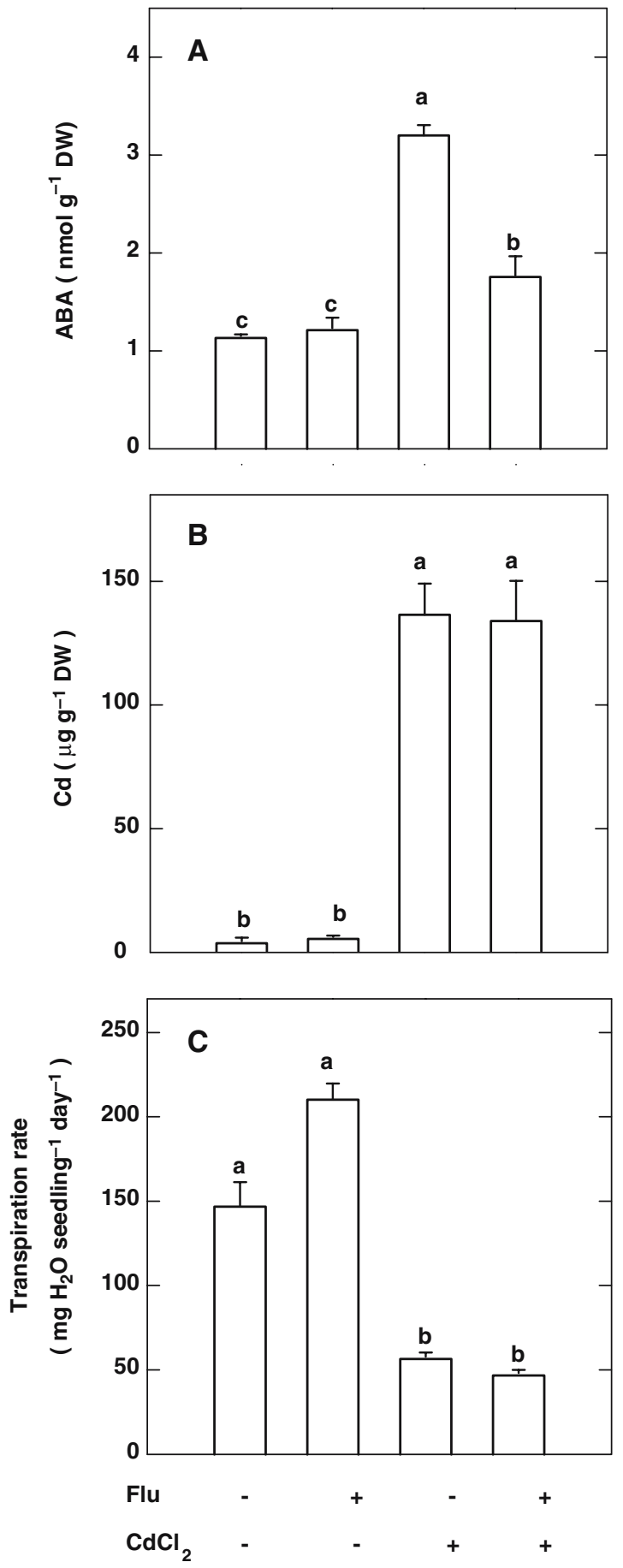

Fig. 7 Effect of fluridone (Flu, $0.2 \mathrm{mM}$ ) on the contents of ABA (A) and $\mathrm{Cd}(\mathbf{B})$ in the second leaves of rice seedlings, and the transpiration rates $(\mathbf{C})$ of the rice seedlings treated with or without $\mathrm{CdCl}_{2}(0.5 \mathrm{mM})$ at $35 /$ $30^{\circ} \mathrm{C}$. All measurements were made 2 days after treatment. Bars indicate standard error $(n=4)$. Values with the same letter are not significantly different at $P<0.05$ 
At low temperature, $\mathrm{CdCl}_{2}$ treatment resulted in an increase in $\mathrm{NH}_{4}^{+}$content, but had no effect on GS activity and PAL specific activity in the second leaves (Figs. 2A-C). Thus, Cd-induced $\mathrm{NH}_{4}^{+}$accumulation in rice seedlings at low
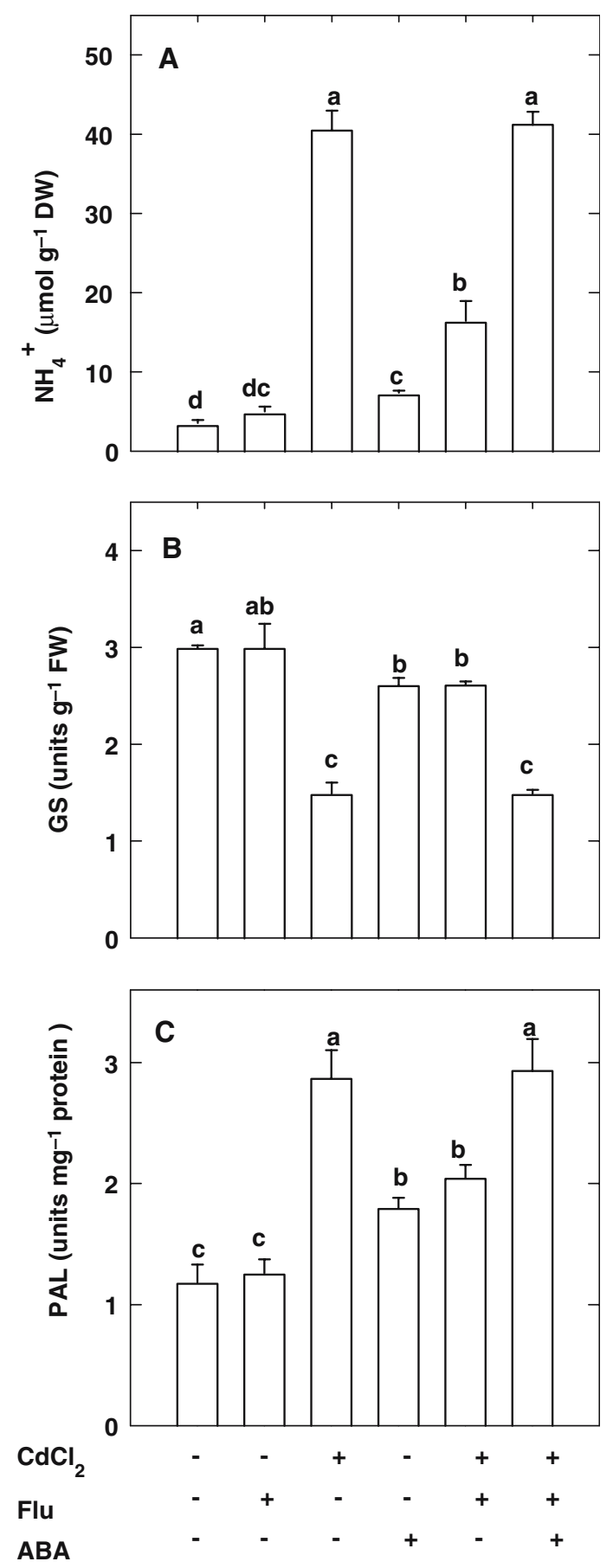

temperature cannot be explained by GS and PAL. Ammonium ion is produced during nitrate assimilation, deamination of amino acids, and photorespiration (Miflin and Lea 1976). Thus, the possibilities that nitrate reduction, deamination of amino acid, and photorespiration may be responsile for $\mathrm{Cd}$-induced $\mathrm{NH}_{4}^{+}$accumulation at low temperature cannot be excluded.

ABA is a sesquiterpenoid derived from xanthophylls (Nambara and Marion-Poll 2005). The level of ABA in plants increases upon their exposure to Cd stress (Fediuc et al. 2005; Hollenbach et al. 1997; Hsu and Kao 2003; Poschenrieder et al. 1989). Here, we show that ABA accumulation in rice leaves is induced by $\mathrm{Cd}$ at high temperature (Fig. 5B). However, high temperature itself does not cause ABA accumulation in rice seedlings leaves (Fig. 5B). It is now well established that ABA in higher plants is derived from $\mathrm{C}_{40}$-carotenoids (Nambara and Morion-Poll, 2005). As Flu is an inhibitor of carotenoid biosynthesis (Kowalczyk-Schröder and Sandmann 1992), the effect of this inhibitor on Cd-induced $\mathrm{ABA}$ in the leaves of rice seedlings at high temperature may imply that ABA biosynthetic pathway in response to $\mathrm{Cd}$ at high temperature appears to be the same as that established in other stress conditions (Nambara and MarionPoll 2005; Zeevaart and Creelman 1988).

The present study indicated that ABA is involved in $\mathrm{Cd}$-induced $\mathrm{NH}_{4}^{+}$accumulation in the leaves of rice seedlings grown at high temperature. This conclusion was based on observations that (a) the increase in endogenous ABA content in response to $\mathrm{Cd}$ in leaves of rice seedlings grown at high temperature was more pronounced than that at medium and low temperatures (Fig. 5B); (b) exogenous application of ABA at medium temperature increased $\mathrm{ABA}$ and $\mathrm{NH}_{4}^{+}$contents in the second leaves (Figs. 6A, B); (c) Flu treatment

Fig. 8 Effect of fluridone (Flu, $0.2 \mathrm{mM})$ and ABA $(5 \mu \mathrm{M})$ on the contents of $\mathrm{NH}_{4}^{+}(\mathbf{A})$, and the activities of GS (B) and the specific activities PAL $(\mathbf{C})$ in the second leaves of rice seedlings treated with or without $\mathrm{CdCl}_{2}(0.5 \mathrm{mM})$ at $35 / 30^{\circ} \mathrm{C}$. All measurements were made 2 days after treatment. Bars indicate standard error $(n=4)$. Values with the same letter are not significantly different at $P<0.05$ 
reduced ABA content, as well as Cd-induced accumulation of $\mathrm{NH}_{4}^{+}$and changes of the activities of enzymes responsible for $\mathrm{NH}_{4}^{+}$accumulation in the leaves of rice seedlings grown at high temperature (Figs. 7A and $8 \mathrm{~A}-\mathrm{C}$ ); and (d) the effects of Flu on $\mathrm{Cd}$-induced $\mathrm{NH}_{4}^{+}$accumulation and enzyme activities related to $\mathrm{NH}_{4}^{+}$accumulation of rice seedlings grown at high temperature can be reversed by the application of ABA (Figs. 8A-C).

The fact that Flu treatment reduced ABA content, but did not reduce $\mathrm{Cd}$ content in leaves of rice seedlings in response to $\mathrm{CdCl}_{2}$ at high temperature (Figs. 7A, B) suggests that Flu effect on the reduction of $\mathrm{Cd}$-induced $\mathrm{NH}_{4}^{+}$accumulation is attributable to reduction of ABA but not $\mathrm{Cd}$ content in leaves of rice seedlings grown at high temperature. These results strengthen further our conclusion that $\mathrm{Cd}$-induced $\mathrm{NH}_{4}^{+}$accumulation at high temperature is mediated through ABA. Recently, Fediuc et al. (2005) reported that ABA mediated the Cd-induced stimulation of $O$-acetylserine (thiol) lyase (OASTL), the enzyme responsible for cysteine biosynthesis. However, in case of growth of Arabidopis (root length and seedlings fresh weight), the magnitude of Cd-induced inhibition in ABA-insensitive mutants was generally comparable to that in the wild type (Sharma and Kumar 2002). Accumulation of proline in response to $\mathrm{Cd}$ has been reported in wheat and Silene vulgaris (Öncel 2002; Schat et al. 1997). We also reported that $\mathrm{NH}_{4}^{+}$accumulation in dark-treated and water-stressed rice seedlings is associated with proline accumulation (Yang and Kao 2000). Our unpublished data indicated that $\mathrm{Cd}$-induced proline accumulation in leaves of rice seedlings grown at high temperature is also mediated through ABA accumulation.

$\mathrm{Cd}$ is known to inhibit transpiration rate of several plants (Hagemeyer et al. 1986; Lamoreaux and Chaney 1978; Schlegel et al. 1987). We also found that $\mathrm{CdCl}_{2}$ treatment reduced transpiration rate of rice seedlings (Fig. 5A). Reduction of transpiration rate and increase in $\mathrm{Cd}$ content caused by $\mathrm{CdCl}_{2}$ in seedlings grown at high temperature were more pronounced than those at medium and low temperatures (Figs. 3B and 5A). Since Flu treatment had no effect on transpiration rate of rice seedlings in response to $\mathrm{CdCl}_{2}$ at high temperature (Fig. 7C). It appears that the decrease of transpiration rate caused by $\mathrm{CdCl}_{2}$ is not attributable to increase in ABA content, but to increase in $\mathrm{Cd}$ content.

Acknowledgements This work was supported by a research grant from the National Science Council of the Republic of China.

\section{References}

Bradford MM (1976) A rapid and sensitive method for the quantitation of microgram quantities of protein utilizing the principle of protein-dye binding. Anal Biochem 72:248-254

Chawla G, Singh J, Wiswanathan PN (1991) Effect of pH and temperature on the uptake of cadmium by Lemna minor L. Bull Environ Contam Toxicol 47:84-90

Cohen CK, Fox TC, Garvin DF, Kochian LV (1998) The role of iron-deficiency stress responses in stimulating heavy-metal transport in plants. Plant Physiol 116:1063-1072

Fediuc E, Lips SH, Erdei L (2005) $O$-Acetylserine (thiol) lyase activity in Phragmites and Typha plants under cadmium and $\mathrm{NaCl}$ stress conditions and the involvement of $\mathrm{ABA}$ in the stress response. J Plant Physiol 162:865-872

Foy CD (1998) Plant adaptation to acid, aluminum-toxic soils. Comm Soil Sci Plant Anal 19:959-987

Greger M, Johansson M (1992) Cadmium effect on leaf transpiration of sugar beet (Beta vulgaris). Physiol Plant 86:465-473

Hagemeyer J, Kahle M, Breckle SW (1986) Cadmium in Fagus sylvatica L. trees and seedlings: leaching, uptake and interconnection with transpiration. Air Soil Pollut 29:347-359

Hahlbrock R, Grisebach H (1979) Enzymic controls in the biosynthesis of lignin and flavonoids. Annu Rev Plant Physiol 30:105-130

Hollenbach B, Schreiber L, Hartung W, Dietz KJ (1997) Cadmium tends to stimulate expression of lipid transfer protein (ltp) in barley: implications for the involvement of LTP in wax assembly. Planta 203:9-19

Hooda PS, Alloway BJ (1993) Effects of time and temperature on the bioavailability of $\mathrm{Cd}$ and $\mathrm{Pb}$ from sludge-amended soils. J Soil Sci 44:97-110

Hsu YT, Kao CH (2003) Accumulation of ammonium ion in cadmium tolerant and sensitive cultivars of Oryza sativa. Plant Growth Regul 39:271-276

Hsu YT, Kao CH (2004) Cadmium toxicity is reduced by nitric oxide in rice leaves. Plant Growth Regul 42:227-238

Hung KT, Kao CH (2005) Hydrogen peroxide is required for abscisic acid-induced $\mathrm{NH}_{4}^{+}$accumulation in rice leaves. J Plant Physiol 162:1022-1029

Hyodo H, Fujinami H (1989) The effect of 2,5-norbornadiene on the induction of the activity of 1-aminocyclopropane1-carboxylate synthase and of phenylalanine ammonialyase in wounded mesocarp tissue of Cucurbita maxima. Plant Cell Physiol 30:857-860 
Javis SC, Jones LHP, Hopper MJ (1976) Cadmium uptake from solution by plants and its transport from roots to shoots. Plant Soil 44:179-191

Kirkham MB (1978) Water relations of cadmium-treated plants. J Environ Qual 7:334-336

Korshunova YO, Eide D, Clark WG, Guerinot ML, Pakrasi HB (1999) The IRT1 protrein from Arabidopsis thaliana is a metal transporter with a broad substrate range. Plant Mol Biol 40:37-44

Kowalczyk-Schröder S, Sandmann G (1992) Interaction of fluridone with phytoene desaturation of Aphanocapsa. Pestic Biochem Physiol 42:7-12

Lamoreaux RL, Chaney WR (1978) The effect of cadmium on net photosynthesis, transpiration and dark respiration of excised sliver maple leaves. Physiol Plant 43:231-236

Lasat MM, Pence NS, Garvin DF, Ebbs SD, Kochian LV (2000) Molecular physiology of zinc transport in the $\mathrm{Zn}$ hypraccumulator Thlaspi caerulescens. J Exp Bot 342:71-79

Lin CC, Kao CH (1996) Disturbed ammonia assimilation is associated with growth inhibition of roots in rice seedlings caused by NaCl. Plant Growth Regul 18:223-238

Macek T, Kotrba P, Suchova M, Skacel F, Demnerova K, Ruml T (1994) Accumulation of cadmium by hairyroot cultures of Solnum nigrum. Biotechnol Lett 16:621-624

Mautsoe PJ, Beckett (1996) A preliminary study of the factors affecting the kinetics of cadmium uptake by the liverwort Dumortiera hirsute. South Afr J Bot 62:332-336

Miflin BJ, Lea PJ (1976) The pathway of nitrogen assimilation in plants. Phytochemistry 15:873-885

Nambara E, Marion-Poll A (2005) Abscisic acid biosynthesis and catabolism. Annu Rev Plant Biol 56:165-185

Oaks A, stolen J, Jones K, Winspear MJ, Booesel IL (1980) Enzymes of nitrogen assimilation in maize roots. Planta 148:477-484

Öncel I, Keles Y, üstün AS (2000) Interactive effects of temperature and heavy metal stress on the growth and some biochemical compounds in wheat seedlings. Environ Pollut 107:315-320

Pence NS, Larsen PB, Ebbs SD, Letham DL, Lasat MM, Garvin DF, Eide D, Kochian LV (2000) The molecular physiology of heavy metal transport in the $\mathrm{Zn} / \mathrm{Cd}$ hyperaccumulator Thlaspi caerulescens. Proc Natl Acad Sci USA 97:4956-4960

Peng S, Huang J, Sheehy JE, Laza RC, Visperas RM, Zhong X, Centeno GS, Khush GS, Cassman KG
(2004) Rice yields decline with higher night temperature from global warming. Proc Natl Acad Sci USA 101:9971-9975

Poschenrieder C, Gunse B, Barcelo J (1989) Influence of cadmium on water relations, stomatal resistance and abscisic acid content in expanding bean leaves. Plant Phsyiol 90:1365-1371

Rauser WE, Dunmbroff EB (1981) Effect of excess cobalt, nickel and zinc on water relation of Phaseolus vulgaris. Envion Exp Bot 21:249-255

Razel RA, Ellis S, Singh S, Lewis NG, Towers GHN (1996) Nitrogen recycling in phenylpropanoid metabolism. Phytochemistory 41:31-35

Sakurai N, Katayama Y, Yamaya T (2001) Overlapping expression of cytosolic glutamine synthetase and phenylalanine ammonia-lyase in immature leaf blades of rice. Physiol Plant 113:400-408

Salt DE, Prince RC, Pickering IJ, Raskin I (1995) Mechanism of cadmium mobility and accumulation in Indian mustard. Plant Physiol 109:1427-1433

Sanitá di Toppi L, Gabbrielli R 1999 Response to cadmium in higher plants. Environ Exp Bot 41:105-130

Schat H, Sharma SS, Vooijs R (1997) Heavy metal-induced accumulation of free proline by a metal-tolerant and a nontolerant ecotype of Silene vulgaris. Physiol Plant 101:477-482

Schlegel H, Godbold DL, Hüttermann (1987) Whole plant aspects of heavy metal induced changes in $\mathrm{CO}_{2}$ uptake and water relations of spruce (Picea abies) seedlings. Physiol Plant 69:265-270

Seo M, Koshiba T (2002) Complex regulation of ABA biosynthesis. Trends Plant Sci 7:41-48

Sharma SS, Kumar V (2002) Responses of wild type and abscisic acid mutants of Arabidopisis thaliana to cadmium. J Plant Physiol 159:1323-1327

van Heerden PS, Towers GHN, Lewis NG (1996) Nitrogen metabolism in lignifying Pinus taeda cell cultures. J Biol Chem 271:12350-12355

Walker-Simmons M (1987) ABA levels and sensitivity in developing wheat embryos of sprouting resistant and susceptible cultivars. Plant Physiol 84:61-66

Weatherburn MW (1967) Phenol-hypochloride reaction for determination of ammonia. Anal Chem 39:971-974

Yang CW, Kao CH (2000) Ammonium in relation to praline accumulation in detached rice leaves. Plant Growth Regul 30:139-144

Zeevaart JAD, Creelman RA (1988) Metabolism and physiology of abscisic acid. Annu Rev Plant Physiol Plant Mol Biol 39:439-473 